\section{2e WORK-RELATED UPPER EXTREMITY MUSCULOSKELETAL DISORDERS IN JAPAN}

S Horie. Department of Health Policy and Management, University of Occupational and Environmental Health, Japan

\subsection{6/oemed-2018-ICOHabstracts.731}

In Japan, compensable occupational diseases are officially listed in Appended table 1 and 2 of Ordinance for Enforcement of the Labour Standards Act. The category No. 3 (diseases caused by work with extreme physical tension) includes a subcategory of (d): musculoskeletal disorders of the back of the head, neck, shoulder girdle, upper arm, forearm, or fingers due to work which require repeated input into a computer or other operation involving excessive tension on the upper limbs. Local labour standard bureau is in charge of judging the work-relatedness. The detailed criterion was first published as a notice from the Labour Standard Bureau, Ministry of Labour on Feb 5, 1975, as 'Judgment criterion for work-relatedness of upper extremity disorders from keypunching work' (Notification No. 59, 1975) and revised on Feb 3, 1997, as 'Judgment criterion for work-relatedness of diseases from upper extremity work' (Notification No. 65, 1997). Target diseases of the criterion include humeral epicondylitis, cubital tunnel syndrome, supinator syndrome, wrist tendonitis, carpal tunnel syndrome and cervico-omo-brachial syndrome (COBS; nonspecific symptoms of neck, shoulder and upper extremity). Three indispensable conditions of the required exposure for determining work-relatedness are:

- long ( $\geq 6$ months in general) and heavy workload to the upper extremity,

- excessive $(\geq 10 \%$ increase, $\geq 20 \%$ increase/day for 10 days/ months or $\geq 20 \%$ increase/hour for $\geq 1 / 3$ hours/day)

workload for 3 months preceding symptoms and

- reasonable time course.

The criterion requires careful and comprehensive judgment of the work-relatedness of individual cases referring to the working environment, heteronomous and restrictive nature of the work, their age, physical strength, life style at home, etc. It recommends avoiding diagnosing as COBS; however, it still allows use of COBS when the specified diagnoses are difficult. According to the workers' compensation statistics in 2016, there were 153 cases of upper extremity diseases out of 7361 cases of occupational diseases in total with 4 or more lost work-days.

\section{$1632 f$ VARIED CRITERIA FOR WORK-RELATED UPPER EXTREMITY DISORDERS IN UNITED STATES}

${ }^{1} \mathrm{D}$ Rempel, ${ }^{2} \mathrm{~K}$ Hegmann, ${ }^{3} \mathrm{R}$ Meister. 'Division of Occupational and Environmental Medicine, University of California at San Francisco, USA; ${ }^{2}$ University of Utah, Rocky Mountain Centre for Occupational and Environmental Health, USA; ${ }^{3}$ California Department of Industrial Relations, Division of Workers' Compensation, Oakland, USA

\subsection{6/oemed-2018-ICOHabstracts.732}

In the US, the acceptance of a claim for a work-related MSD is most commonly determined by the employer and insurance carrier with input from the physician's report. For most workers, the process is based on state laws, which vary from state to state. Some states (e.g., California) have adopted the ACOEM Medical Practice Guidelines (2nd Ed, 1). The
Guidelines recommend a process for determining work-relatedness based on evidence of disease, evidence of exposure, epidemiology, and other factors (e.g., non-workplace exposures). For example, the diagnosis of carpal tunnel syndrome (CTS) should consider the presence of numbness/tingling in the median nerve distribution, electrodiagnostic studies (EDS), if available, and non-work factors such as age and BMI. Workrelatedness for CTS and other non-traumatic hand/wrist disorders (e.g., tendinosis, tendinitis, trigger digit) generally requires sustained or repeated forceful $(>10 \mathrm{~N})$ pinching or gripping and the Guidelines refer to the ACGIH HAL TLV as a risk assessment tool. Other MSDs discussed include epcondylalgia (epicondylosis), ligament sprains, tenosynovitis/tendinosis (including 0de Quervain's), trigger digit, hand arm vibration syndrome (HAVS), ulnar and radial nerve entrapment, ganglion cyst and non-specific hand/wrist/forearm pain. Colorado State developed treatment guidelines for CTS (38-pages), with provisions that are enforceable under workers' compensation rules (2). The roles of history, physical examination and EDS in diagnosis and management are spelled out. For determining work-relatedness, job title alone is not sufficient. Six specific ergonomic hazards, with minimum daily exposure durations (e.g., pinching $>18 \mathrm{n}$ more than 3 hour per day) are listed. Washington State has a 13-page diagnosis and treatment guideline for CTS. Diagnosis requires both appropriate symptoms and an abnormal EDS. Work-related risk factors are listed but without the exposure thresholds provided in the Colorado guidelines. Thus, determinations of worker's compensation cases vary from state to state and these differences could influence comparative research studies.

\section{PHYSICAL ACTIVITY AND WORK}

Fehmidah Munir. School of Sport, Exercise and Health Sciences, Loughborough University, Loughborough, UK

\subsection{6/oemed-2018-ICOHabstracts.733}

Aim of special session To present recent data on work-related physical activity and sedentary behaviour and their effects on health and work-related outcomes

Presenters: F Munir

School of Sport, Exercise and Health Sciences, Loughborough University, Loughborough, UK

\section{$1615 a$ THE EFFECTIVENESS OF WORKPLACE TEAM SPORTS INTERVENTION ON EMPLOYEE WORK, HEALTH AND WELL-BEING}

F Munir*. Loughborough University, Loughborough UK

\subsection{6/oemed-2018-ICOHabstracts.734}

Introduction Workplace Physical activity interventions can positively influence employee health and well-being outcomes. However, research to date is yet to comprehensively examine the efficacy of sport and team sport on health outcomes. Participation in workplace team sport has the capacity to improve not only individual health, but also social group and organisational health outcomes. This study evaluated the impact of a workplace team sport intervention. The primary outcome was aerobic fitness (estimated VO2 max). Secondary outcomes 